\section{Phytotoxicity of the Systemic Insecticide Imidacloprid on Tomato and Cucumber in the Greenhouse}

\author{
Robert C. Ebel, ${ }^{1}$ \\ Byron Wallace, ${ }^{2}$ and \\ Charles Elkins ${ }^{3}$
}

AdDITIONAL INDEX WORDS. Marathon

Summary. I midacloprid is a long-term systemic insecticide that is currently labeled under the trade name $M$ arathon (imidacloprid, 1-[(6-chloro-3pyridyl)methyl-4,5-dihydro- $\mathrm{N}$-nitro1-H -imidazol-2-amine, 1\% granular on fritted clay, B ayer Corp., Kansas City, M o.) for ornamental crops grown in greenhouses. The company that markets $M$ arathon is seeking to expand its label to greenhouse-grown vegetable crops, although the rates they plan to label have not yet been divulged. M arathon was applied to cucumber ( $C$ ucumissativus L. 'Turbo') and tomato (Lycopersicon esculentum Mill. 'R utgers') at $0,1 / 8$, $1 / 4,1 / 2,3 / 4$, and 1 tsp $(0,5,10,20$, 30 , and $40 \mathrm{mg}$ a.i.) per 4.5 -inch (550$\mathrm{mL}$ ) pot. Both species developed phytotoxicity symptoms of leaf chlorosis of the oldest leaves and distorted growth and marginal necrosis of newer leaves within 1 week after application. By the end of the experiment, even the lowest rate caused phytotoxicity symptoms. The symptoms were similar in appearance to $\mathrm{C}$ a deficiency but cucumber foliar analysis revealed no difference in $C a$, $\mathrm{Zn}, \mathrm{Fe}$, or $\mathrm{Co}$ across imidacloprid rates, however, $\mathrm{Mg}$ and $\mathrm{B}$ decreased whereas $K$ and $M \mathbf{n}$ increased linearly across imidacloprid rates. $\mathbf{P}, \mathrm{C} u$, and

The cost of publishing this paper was defrayed in part by the payment of page charges. U nder postal regulations, this paper therefore must be hereby marked advertisement solely to indicate this fact.

${ }^{1}$ Assistant professor, D epartment of $\mathrm{H}$ orticulture, 101 Funchess H all, Auburn U niversity, Auburn, AL 36849

${ }^{2}$ Assistant superintendent and ${ }^{3}$ superintendent, Plant Science Research Center, Auburn U niversity, Auburn, AL 36849.
M o varied quadratically with $1 / 2$ tsp (20 $\mathrm{mg}$ a.i.) per pot having the lowest $P$ and $M O$, and $C u$ increasing at the higher rates. $T$ hese data indicate that imidacloprid can alter plant nutrition. The rates of imidacloprid applied here are not recommended for use on greenhouse-grown cucumber and tomato under similar growing conditions as in this study.

midacloprid is a new, longterm, systemic insecticide that

is highly effective against a wide range of sucking insects and some species in the Coleoptera, Diptera and L epidoptera orders (M ullins, 1993). $M$ arathon, the only formulation of imidacloprid that is labeled for greenhouse use, is currently registered for ornamental plants. We applied imidacloprid to tomato and cucumber at the rates labeled for ornamental crops of $1 / 4$ tsp (10 mg) per 4.5-inch ( $550-\mathrm{mL}$ ) pot but found leaf chlorosis and marginal necrosis and suspected that imidacloprid was the cause.

M ost research reports on imidacloprid havebeen on field-grown plants, including tomato and cucumber, and most have not reported phytotoxicity symptoms ( L utzinsky et al., 1996; M arcano and Gonzalez, 1993). O nly two reports were found that indicated phytotoxicity by imidacloprid, a reduction in seed germination of sugar beets (D ewar et al., 1997) and marginal leaf necrosisof cauliflower ( $N$ atick et al., 1996). The following study was conducted to determine whether imidacloprid caused the damage to cucumber and tomato that we previously observed.

\section{Materials and methods}

Plant culture. The experiments were conducted in 1997 in an uncoated glasshouse in Auburn, Ala. $\mathrm{D}$ ay/ night temperaturesaveraged 82.4 ${ }^{\circ} \mathrm{F} / 71.6^{\circ} \mathrm{F}\left(28^{\circ} \mathrm{C} / 22^{\circ} \mathrm{C}\right)$, respectively. Relativehumidity never dropped below 40\% Plants were grown in sphagnum peat moss (75\%to $85 \%$ by vol.) with the rest consisting of perlite, vermiculite, and dolomitic and calcitic limestonemedium (Pro-M ix 'BX', Premier, R ed H ill, Pa.).

TOMATO EXPERIMENT. O n 1 July, 'R utgers' to mato seedswere sown into a single, 72-count seedling tray that was misted every $2 \mathrm{~h}$ during the day to maintain high relative humidity. After germination, the seedlings were fertil- 


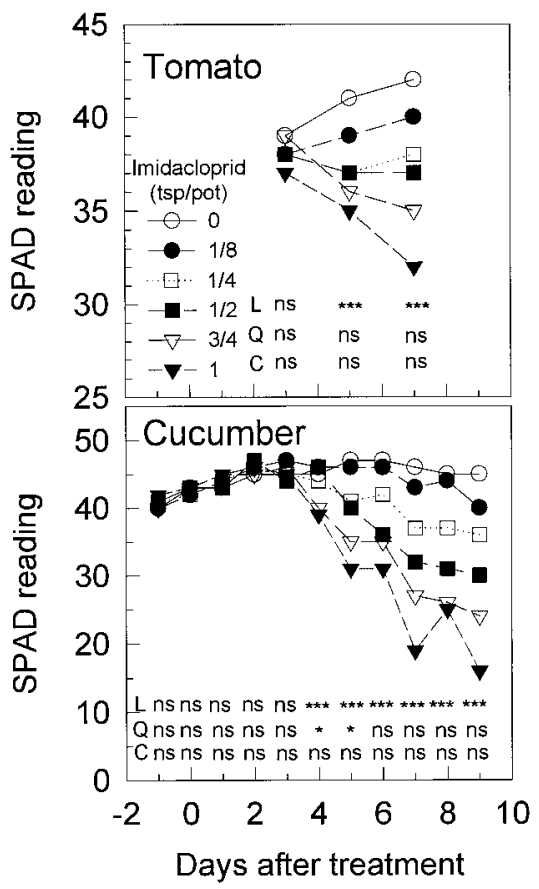

Fig. 1. Effect of soil-applied imidacloprid ( $1 \%$ granular on fritted clay) on chlorosis measured by a SPAD meter of the oldest leaf of tomato and cucumber. $L, Q$, and $C$ represent significance of linear, quadratic, and cubic relationships within date across imidacloprid treatments. ${ }^{a s, *, * * *, * * *}$ onsignificant or significant at $P=0.05,0.01$, or 0.001 , respectively. Significant linear relationships indicate that plant response increased or decreased in a straight line across imidacloprid treatments. Significant quadratic relationships indicate that plant response increased to some maximum and then decreased. T reatments were $0,5,10,20,30$, and $40 \mathrm{mg}$ a.i. per 4.5-inch $(550-\mathrm{mL})$ pot.

ized once to drip with $0.021 \mathrm{oz} / \mathrm{gal}$ (11.4 mm) N as $15 \mathrm{~N}-2.2 \mathrm{P}-12.5 \mathrm{~K}$ (Cal-M ag Peters' Excel, Scotts-Sierra, $\mathrm{H}$ orticultural Products $\mathrm{C}$., $\mathrm{M}$ arysville, O hio). Seedlings were selected for uniformity and transplanted into 48 4.5-inch standard square pots. Each pot received $15 \mathrm{~N}-2.2 \mathrm{P}-12.5 \mathrm{~K}$ using Cal-M ag Peters' Excel every $3 \mathrm{~d}$ for the duration of the experiment.

The experiment was conducted as a randomized complete block design with eight blocks, six imidacloprid treatments and single plant replicationswithin each block. $M$ arathon was broadcast on the potting media surface on 25 J uly 1997 at $0,1 / 8,1 / 4,1 /$ $2,3 / 4$, and 1 tsp $(0,5,10,20,30$, and $40 \mathrm{mg}$ a.i.) per 4.5 -inch pot.

Cucumber experiment. 'Turbo' cucumber seeds were sown on 14 Aug. 1997 with four seeds placed in each of 48 4.5-inch square pots. Plants were watered daily to drip. Four days after seeding, plants were thinned to two plants per pot and on 25 Aug. plants were selected for uniformity and thinned to one plant per pot by severing the other plant at the soil line so as not to disturb the root system of the remaining plant. Plants were fertilized to drip on 21 Aug., 26 Aug., and 1 Sept. with 0.022 oz/ gal N (11.8 mm) as 15N-7.0P-14.1K (Peter'sPeat-Lite fertilizer, Scotts-Sierra, H orticultural Products $\mathrm{Co}$., $\mathrm{M}$ arysville, $\mathrm{OH}$ ). The experimental design and $M$ arathon application rates were the same as that in the tomato experiment. $M$ arathon was applied on 26 Aug.

Data collection. Chlorosis of the oldest leaves was estimated by light absorption at $650 \mathrm{~nm}$ and $940 \mathrm{~nm}$ and measured at 1- to 3-d intervals after treatment using a SPAD light meter (model 502, M inolta, Japan).

Tomato and cucumber plants were harvested $10 \mathrm{~d}$ after treatment on 25J uly and 5 Sept., respectively, which corresponded to $10 \mathrm{~d}$ after treatment application. All leaves were removed from the stems and total leaf surface area was determined using a leaf area meter (model LI-3100; LI-C O R, L incoln, N eb.). N ecrotic areas of leaves were excised using a surgical scissors and total leaf area of the undamaged portion of the leaves determined. L eaves and shoots were dried for $48 \mathrm{~h}$ at 167 to $185^{\circ} \mathrm{F}$ ( 75 to $85^{\circ} \mathrm{C}$ ) and weighed. Leaves from the cucumber experiment were ground in a Wiley $\mathrm{M}$ ill and nutrient content determined byan inductively coupled argon plasma spectrometer (model ICAP 9000; Thermo-J arrell-A sh, Franklin, $M$ ass.) according to the procedure of $\mathrm{H}$ ue and Evans (1986).

Statistical analysis. Data were analyzed as a randomized complete block design using the $G$ eneral L inear Models procedure of the Statistical AnalysisSystem (SASI nstitute, 1988). Significance of linear, quadratic and cubic polynomialswere determined to ascertain the trend of plant responses across imidacloprid treatments.

\section{Results and discussion}

Phytotoxic symptoms developed on all imidacloprid treatments within 1 week after application. L eaf chlorosis decreased linearly across imidacloprid treatments starting 5 and $4 \mathrm{~d}$ after treatment for tomato and cucumber, respectively, although there was also a significant quadratic relationship for cucumber 4 and $5 \mathrm{~d}$ after treatment because chlorosis of the low imidacloprid rates took longer to develop (Fig. 1). Chlorosis as measured

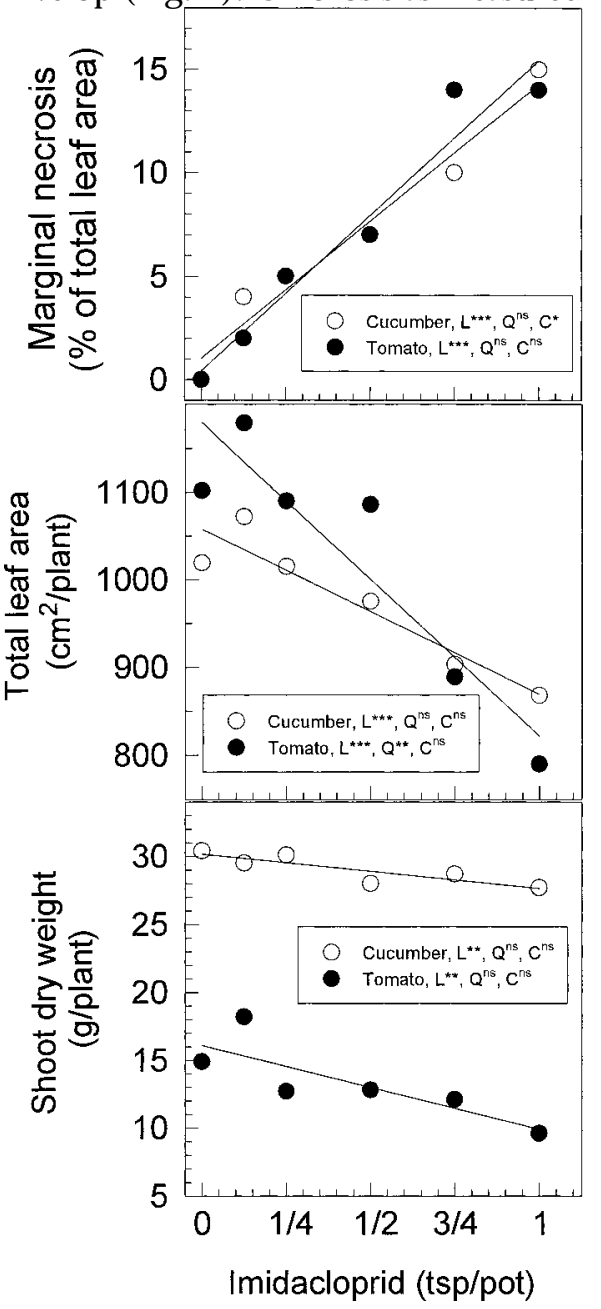

Fig. 2. M arginal leaf necrosis and reduction in whole plant growth measured by total leaf area and shoot dry weight in cucumber and tomato $10 \mathrm{~d}$ after imidacloprid application ( $1 \%$ granular on fritted clay) to soil. $L, Q$, and $C$ represent significance of linear, quadratic, and cubic relationships, respectively.

${ }_{N s, * * * *, * * *} \mathrm{~N}$ onsignificant or significant at $P=0.05,0.01$, or 0.001 , respectively. Significant linear relationships indicate that plant response increased or decreased in a straight line across imidacloprid treatments. Although some quadratic and cubic relationships were significantly different, the strongest relationship for all responses was linear, so this relationship was chosen for representation. Treatments were $0,5,10,20,30$, and $40 \mathrm{mg}$ a.i. per 4.5 -inch $(550-\mathrm{mL})$ pot. 
T able 1. Effect of soil-applied imidacloprid ( $1 \%$ granular on fritted clay) on nutrient content of cucumber leaves $10 \mathrm{~d}$ after treatment.

\begin{tabular}{|c|c|c|c|c|c|c|c|c|c|c|c|}
\hline \multirow{2}{*}{$\begin{array}{l}\text { I midacloprid } \\
{\text { (tsp/pot })^{z}}\end{array}$} & $\mathbf{P}$ & $\mathbf{K}$ & $\mathrm{Ca}$ & $\mathbf{M g}$ & $M n$ & B & Zn & $\mathbf{F e}$ & Co & $\mathrm{Cu}$ & Mo \\
\hline & \multicolumn{4}{|c|}{ (\%) } & \multicolumn{7}{|c|}{$\left(\mathrm{mg}^{\prime} \mathrm{g}^{-1}\right.$ dry wt) } \\
\hline $0^{z}$ & 1.02 & 3.05 & 2.4 & 0.59 & 157 & 50 & 78 & 159 & 0.71 & 7.2 & 7.5 \\
\hline $1 / 4$ & 0.91 & 2.91 & 2.4 & 0.53 & 171 & 45 & 78 & 172 & 0.86 & 7.9 & 5.3 \\
\hline $1 / 2$ & 0.90 & 3.01 & 2.4 & 0.51 & 171 & 45 & 76 & 146 & 0.67 & 8.5 & 4.5 \\
\hline $3 / 4$ & 0.95 & 3.34 & 2.3 & 0.46 & 191 & 44 & 77 & 150 & 0.72 & 9.9 & 4.9 \\
\hline \multicolumn{12}{|l|}{ Significance } \\
\hline L & NS & $*$ & NS & $* * *$ & $* * *$ & $* *$ & NS & NS & NS & NS & $*$ \\
\hline Q & $*$ & NS & NS & NS & NS & NS & NS & NS & NS & $* *$ & $* *$ \\
\hline
\end{tabular}

$\mathrm{z}_{0}, 5,10,20,30$, and $40 \mathrm{mg}$ a.i. per 4.5 -inch $(550-\mathrm{mL})$ pot.

YL inear relationships indicate that plant response increased or decreased in a straight line across imidacloprid treatments, significant quadratic relationships indicate that plant response increased to some maximum and then decreased again, or decreased to some minimum and then increased again. $\mathrm{N}$ one of the cubic relationships were significant; 1 $\mathrm{mg} \cdot \mathrm{g}^{-1}=0.016 \mathrm{oz} / \mathrm{lb}$.

$\mathrm{Ns}^{*},{ }^{* *},{ }^{* * *} \mathrm{~N}$ onsignificant or significant at $\mathrm{P}=0.05,0.01$, or 0.001 , respectively.

by the SPAD meter has been shown to be directly correlated with nitrogen and leaf chlorophyll content (Schepers et al., 1992; Wood et al., 1992) and photosynthetic rate ( $M$ a et al., 1995). By the end of each experiment, there was a linear relationship in chlorosis across imidacloprid treatments.

$\mathrm{N}$ ewly emerging leaves were distorted especially near the edges forming acup-shapeon cucumber but across the entire leaf on tomato within $5 \mathrm{~d}$ after treatment. Leaf cupping and marginal necrosis was most severe on the oldest leaves and diminished towards the shoot tip. Leaf necrosis was visible $7 \mathrm{~d}$ after treatment on both species and was most severe on oldest leaves. By the end of each experiment, the percent of total leaf area that exhibited marginal necrosisincreased linearly across imidacloprid treatments, although the cubic relationship was also significant for cucumber (Fig. 2).

Whole plant growth was reduced by imidacloprid at the end of both experiments. Total leaf area and shoot dry weight decreased linearly across imidacloprid treatments. Thequadratic relationship was significant for total leaf area of tomato with leaf area not strongly affected above $1 / 2$ tsp ( $20 \mathrm{mg}$ a.i.) per pot but decreased steeply below that rate. The root systems were observed to besmaller on imidacloprid treated plants, but they did not appear to be distorted compared to the controls.

The phytotoxic symptoms of leaf marginal necrosis, malformed leaves, and reduced shoot growth are similar to those of $\mathrm{C}$ a deficiency in cucumber (Locascio, 1996), however, leaf foliar
Ca of treated plants were similar to the controls(Table 1 ). $K$ and $M n$ increased whereas $\mathrm{Mg}$ and $\mathrm{B}$ decreased linearly across imidacloprid rates. $\mathrm{P}, \mathrm{Cu}$, and Mo varied quadratically with $1 / 2$ tsp (20 mg a.i.) per pot having the lowest $\mathrm{P}$ and $\mathrm{MO}$, and $\mathrm{Cu}$ increasing at the higher rates. It is clear that the imidacloprid treatments altered plant nutrition, however, typical deficiency symptoms of those that differed are not similar to the damage observed in this study. Thus, differences in plant nutrition are likely a result and not a cause of the phytotoxicity symptoms.

I midacloprid has been shown to have a half-life of $<3 d$ when injected into stems of cucumbers (I shii et al., 1994). This short half-life likely indicates that imidacloprid is directly catabolized by the plant, especially considering that the half-life in soil is considerably greater, up to $150 \mathrm{~d}$ (M ullins, 1993). It appears that excess imidacloprid in the plant disrupts metabolism sufficiently to cause senescence of older leaves and abnormal development of new leaves that culminates in marginal necrosis. The maximum amount of imidacloprid that plants can tolerate needs to be determined and probably varies by species and cultivar.

The phytotoxic symptoms reported here are similar to those reported by N atwick et al. (1996), and their procedure was somewhat similar to ours. They drenched roots of cauliflower seedlings in flats with as little as $2.57 \mathrm{oz}$ imidocloprid/ acre (180 ga.i./ ha), transplanted the seedlings into the field $12 \mathrm{~h}$ later, and found that marginal leaf necrosisdeveloped within
2 weeks after application. H owever, they found phytotoxicity at only one of two field locations so other factors in the growing environment apparently affect development of symptoms.

Olympic H orticultural Products (Bradenton, $\mathrm{Fla}$.), the marketing company for Bayer Corp. (Kansas City, $M$ o.), is seeking to expand the label of $M$ arathon for use on vegetable crops in the greenhouse, but they have not divulge publically the rates they plan to label. The rates of imidacloprid applied in this study are not recommended for useon greenhouse-grown cucumber and tomato under growing conditionssimilar to thosein thisstudy. Since growing conditions apparently affect sensitivity of plants to imidacloprid, we are conducting studies to determine what conditions result in phytotoxicity.

\section{Literature cited}

Dewar, A.M., F. Westwood, K.M. Bean, L.A. H aylock, and R. O sborne. 1997. The relationship between pellet size and the quantity of imidacloprid applied to sugar beet pelletsand the consequencesfor seedling emergence. Crop Prot. 16:187-192.

H ue, N.V. and C.E. Evans. 1986. Procedures used by the Auburn U niversity Soil Testing Laboratory. Ala. Agr. Expt. Sta. D ept. Agron. Soils Series 106.

I shii, Y., I. Kobori, Y. Araki, S. Kurogochi, K. I waya, and S. Kagabu. 1994. H PLC determination of the new insecticide imidacloprid and its behavior in rice and cucumber. J. Agr. Food Chem. 42:29172921.

Locascio, S.J . 1996. Cucurbits: Cucumber, muskmelon, and watermelon. In: W.F. 
Bennett (ed.). Nutrient deficiencies and toxicities in crop plants. The Amer. Phytopathol. Soc., St. Paul, M inn.

Lutzinsky, U., M. H ama, and R. Roso. 1996. The use of coloured plastics to reduce the incidence of tomato yellow leaf curl virusin market tomatoes. Plasticulture 112:21-22.

Ma, B.L., M.J. Morrison, and H.D. Voldeng. 1995. Leaf greenness and photosynthetic rates in soybean. Crop Sci. 35:1411-1414.

M arcano, R. and E. Gonzalez. 1993. Evaluacion de insecticidas para el control de la mosca blanca Bemisia tabaci (Gennadius), en tomate. Boletin de Entmologia Venezolana 8:123-132.

M ullins, J.W. 1993. I midacloprid. A new nitroguanidine insecticide, chapter $13 . \mathrm{In}$ : S.O. D uke, J.J. M enn, and J.R. Plimmer (eds.). Pest control with enhanced environmental safety. Amer. Chem. Soc., Wash., D.C.

N atick, E.T., J.C. Palumbo and C.E. Engle. 1996. E ffects of imidacloprid on colonization of aphids and silverleaf whitefly and growth, yield and phytotoxicity in cauliflower. Southwestern Entemologist 21:283-292.

SAS Institute. 1988. SAS/ STAT user's guide. release 6.03. SAS Inst., Cary, N.C.

Schepers, J.S., D .D . Francis, M . Vigil, and F.E. B elow. 1992. Comparison of corn leaf nitrogen concentration and chlorophyll meter readins. Comm. Soil Sci. Plant Anal. 23:2173-2187.

Wood, C.W., P.W. Tracy, D.W. Reeves, and K.L. Edmisten. 1992. Determination of cotton nitrogen status with a hand-held chlorophyll meter. J. Plant N ut. 15:14351448. 